\title{
Analysis of the Impact of Artificial Intelligence Application on the Development of Accounting Industry
}

\author{
Jiaxin Luo, Qingjun Meng, Yan Cai \\ School of Business, University of Hohai, Nanjing, China \\ Email: 15850677099@163.com
}

How to cite this paper: Luo, J.X., Meng, Q.J. and Cai, Y. (2018) Analysis of the Impact of Artificial Intelligence Application on the Development of Accounting Industry. Open Journal of Business and Management, 6, 850-856.

https://doi.org/10.4236/ojbm.2018.64063

Received: July 30, 2018

Accepted: August 28, 2018

Published: August 31, 2018

Copyright ( 92018 by authors and Scientific Research Publishing Inc. This work is licensed under the Creative Commons Attribution International License (CC BY 4.0).

http://creativecommons.org/licenses/by/4.0/

\section{Open Access}

\begin{abstract}
With the rapid development of information technology and the needs of economic society, artificial intelligence has ushered in the golden age. The application of artificial intelligence technology in the accounting field is an inevitable trend, which will bring tremendous changes and development to the accounting industry. This paper takes the application of artificial intelligence in the accounting industry as the research object, analyzes the impact of artificial intelligence on the development of accounting industry, and puts forward relevant suggestions for its existing problems.
\end{abstract}

\section{Keywords}

Artificial Intelligence, Accounting, Transformation

\section{Introduction}

In 1956, at the University of Dartmouth seminar in the United States, John McCarthy and other computer experts first proposed the concept of "artificial intelligence" [1], marking the birth of artificial intelligence. Nowadays, with the wave of artificial intelligence sweeping across the globe, the International Joint Conference on Artificial Intelligence continues to research related technologies, and the world's major developed countries regard the development of artificial intelligence as a major strategy to enhance national competitiveness. In 2017, artificial intelligence was first written into the Chinese government work report, and 15 departments including the Ministry of Finance worked together to build the world's major artificial intelligence innovation center [2]. Nowadays, artificial intelligence technology has been widely used in agriculture, commerce, education, and service industries. The golden age of artificial intelligence has ar- 
rived.

With the rapid development of artificial intelligence technology and its wide application in various fields, the trend of human work being replaced by robots is intensifying. The involvement of artificial intelligence in the accounting industry will inevitably affect and subvert the traditional development mode and bring innovation to the accounting industry. The 2017 Chinese Government Work Report promoted the development of artificial intelligence to the national strategic level, clearly pointing out the need to accelerate the development and transformation of artificial intelligence technology; the State Council issued the "New Generation Artificial Intelligence Development Plan" to promote the integration of artificial intelligence and various industries, promote large-scale application of artificial intelligence, and comprehensively enhance the level of intelligent development of industry [3]. In February 2018, the "Standards for the Training and Evaluation of Accounting Practice Information Application Capabilities" was approved in Beijing. Its normative content covers two sections: artificial intelligence application and management accounting information application. The support of relevant policies and the issue of regulations mean that the combination of artificial intelligence and accounting industry is an inevitable trend in the future.

In 2016, Deloitte Touche Tohmatsu, one of the world's four largest accounting firms, announced the introduction of artificial intelligence into accounting, taxation, and auditing [4]. In 2017, Nigel Duffy, a world-renowned machine learning and artificial intelligence expert, joined Ernst \& Young as the person in charge of its global innovative artificial intelligence team. In recent years, many countries have been competing to carry out research and application of artificial intelligence, and the call for the use of artificial intelligence is louder and louder in academia. Professor Sun Zheng, former president of Shanghai University of Finance and Economics, put forward the view that enterprises should use the Internet and big data for transformation and innovation in the speech of "Financial Transformation and Evolution in the Period of VUCA"; in the keynote speech of "New Era, New Challenges, New Changes", Professor Qin Rongsheng, secretary of the Party Committee of Beijing National Accounting Institute, declared that financial management should be intelligent in the future financial management transformation of enterprises; Li Wei, an expert in China's management accounting informationization, pointed out that the deep application of artificial intelligence in the financial field is the general trend of financial intelligence in the future. Facing the transformation and upgrading of the accounting industry, the traditional accounting work has the characteristics of repetition and cumbersome. The application of artificial intelligence can solve the pain points of inefficiency and low added value in the accounting field, making the accountants turn to more creative work and bring greater value to the company. In summary, the application of artificial intelligence to the accounting industry will promote the development and innovation of the industry and enhance the competitiveness of enterprises, which is of great significance. 


\section{Problems of the Application of Artificial Intelligence in the Accounting Field}

\subsection{Lack of Experience in the Initial Stage}

At present, the application of artificial intelligence in the field of accounting in China is still in its infancy. Although more and more units have introduced accounting robots, these robots are just a kind of operation of process automation technology with clear algorithm, which is suitable for a large number of repeated operation scenarios without the ability of deep learning, which is essentially "weak AI". Currently, the application of automation technology is more extensive, and the application scope is mainly at the level of financial reporting. It has not yet entered the core areas of accounting such as financial analysis, and has not yet exerted an influence that can drive the change of accounting standards [5]. When artificial intelligence is put into accounting work, it must replace every work step of traditional accounting, including the input of original documents, the formation of accounting information, the generation of financial reports, and appropriate decision-making suggestions, so as to truly improve the overall financial work [6]. Therefore, whether it is the depth or breadth of artificial intelligence, the application of artificial intelligence in the accounting industry is still in its infancy, and the complexity of artificial intelligence technology and the lack of application experience have brought great difficulties to its development. Therefore, there is still a long way to go for the development of AI in the accounting field.

\subsection{High Investment with Slow Return}

For enterprises, in order to introduce artificial intelligence into the accounting field, it is necessary to design a unique artificial intelligence system that conforms to the characteristics of the enterprise according to the actual situation of the enterprise. First of all, capital investment is the most important guarantee; secondly, after the introduction of technology, it is necessary to adjust the management of human resources and the daily operation mode of the enterprise. Finally, when the intelligent transformation of the accounting information system is completed, a series of training should be carried out, including the training for the use of new system features and the training of information security [7]. Due to the personalized features of intelligent systems, enterprises need a large amount of resources in the initial application and later operation, which poses great challenges to the cost control of enterprises. Given the high investment and slow return, many enterprises may focus on short-term profits instead of making strategic adjustments and thus stop at the introduction of artificial intelligence technology.

\subsection{The Quality of Professional Talents Needs to Be Improved}

The application of artificial intelligence technology in the accounting field requires the corresponding professional talents to manage, and the current se- 
nior accounting talents in China are scarce. It is estimated that as of 2015, China's accountants reached 20.5 million, accounting graduates with a bachelor degree or above accounted for $23.11 \%$, and there are 100,000 certified public accountants [8]. At this stage, the structural contradiction of Chinese accounting talents is outstanding: the general basic accounting personnel are surplus while the top accounting talents are in short supply. The combination of artificial intelligence and accounting work puts higher demand on accountants. Accounting personnel not only need professional knowledge in accounting field, but also need to master information technology, acquire the skillful use of accounting software and data management, so as to adapt the changes of new work situation.

\subsection{Accounting Personnel Training Program in Colleges Needs Adjustment}

Nowadays, most universities have set relevant courses in accounting computerization. However, influenced by many internal and external factors, there are some problems such as the unitary contents of courses, the disconnection between theoretical knowledge and practical application, and the difficulty of forming scientific computerization system, which cannot meet the requirements of the development of the times [9]. College graduates are the main force of the accounting field in the future. However, at present, the talent training programs in Chinese universities fail to make corresponding adjustments in the context of accounting reform, lack information technology courses related to artificial intelligence, and pay less attention to the innovation of accounting concepts. This will lead to the lack of market competitiveness of college graduates and the inability to meet the market demand of the accounting industry in the future.

\section{Suggestions on Improving the Effectiveness of Artificial Intelligence Application in Accounting Field}

\subsection{The Government Vigorously Supports the Application of Artificial Intelligence in the Accounting Field}

With the general trend of economic globalization, the links and cooperation between countries are getting closer and closer, meanwhile, the competition is becoming more intense. To be competitive in the international stage, China's accounting industry must constantly improve the level of the accounting industry. At present, China has raised the development of artificial intelligence to the national strategic level. The government should also implement relevant plans and measures in various industries and actively create favorable environmental conditions for the development of artificial intelligence in the accounting field. Relevant policies and regulations are needed to encourage and guide the application of artificial intelligence in the accounting industry. For example, enterprises that actively apply artificial intelligence technology should be given appropriate subsidies or tax reduction. 


\subsection{Enterprise Management Attaches Great Importance to the Application of Artificial Intelligence Technology}

At present, technology giants such as Apple, Google, and Microsoft are investing more and more resources to seize the artificial intelligence market. The domestic Internet leader "BAT" is also actively deploying artificial intelligence and applying this technology to more life scenarios. For example, Alibaba's face recognition technology in payment and financial services, and intelligent robot customer service on the shopping platform, these specific applications of artificial intelligence technology have driven the transformation and upgrading of business and services. Artificial intelligence has become a new focus for enterprises to improve their core competitiveness. Therefore, enterprises should look upon artificial intelligence from the perspective of the overall situation, and cooperate with cloud computing and big data analysis technology to make good use of resources. Applying artificial intelligence at the accounting level will increase the cost of the enterprise in the short term, but looking forward to the future, it will enable the company to have more sustainable development capabilities and will occupy a place in the future of artificial intelligence.

\subsection{Improve the Quality of Accounting Education in Colleges}

Colleges and universities should arrange major courses reasonably and scientifically according to their teaching objectives, and design systematic professional training programs. On the one hand, colleges need to attach great importance to the combination of students' theoretical knowledge and accounting practice, strengthen cooperation between universities and enterprises, and strive to create practical opportunities to improve students' practical ability and cultivate applied accountants. On the other hand, colleges should constantly improve the quality of teachers. Teachers should always keep abreast of the changes and trends in the development of international financial standards and accounting in order to make accounting classroom teaching and practical teaching keep pace with the development of the times [10]. Only by striving to improve the teaching level can we cultivate excellent accounting talents that meet market demands.

\subsection{Accounting Talents Establish the Idea of Life-Long Learning}

Accountants should pay attention to the improvement of personal professional skills and the cultivation of professional ethics, and establish the idea of life-long learning to adapt to the rapid changes and development requirements of the accounting industry in the future. The " $13^{\text {th }}$ Five-Year Plan for Accounting Reform and Development" proposes to promote the widespread application of management accounting and implement the accounting talent strategy [11], which has pointed out the direction for the development of accounting talents in China. At present, China's accounting industry is in the transitional stage from basic financial accounting to management accounting. Accounting personnel should change their concepts, actively study and creatively apply artificial intelligence 
and other related knowledge, and strive to become a high-level comprehensive accounting talent, in order to avoid being eliminated by the market.

\section{Conclusion}

As one of the important representatives of the new round of scientific and technological revolution, artificial intelligence is moving from technology research and development to industrial application, and has become a new driving force for global economic development. At present, China's economic development has entered a new normal and the Chinese government has laid out the artificial intelligence industry in many aspects. The accounting industry should also strengthen the main position of artificial intelligence application in the process of reform and innovation. For enterprises, making good use of the new information technology will be the key to capturing opportunities and upgrading in the new era. Undoubtedly, intelligent finance and accounting is the future development trend. In the process of promoting the application of artificial intelligence in the accounting field, it is necessary for the country, enterprises, universities, individuals and other parties to work together, and how to effectively solve the problems arising in the process of application will be the key.

\section{Fund Project}

2018 "Project of the National College Student Innovation and Entrepreneurship Training Program" of Hohai University: "Analysis of the Complex Relationship between R\&D Investment and Innovation Performance of Artificial Intelligence Companies" (No. 69).

\section{Conflicts of Interest}

The authors declare no conflicts of interest regarding the publication of this paper.

\section{References}

[1] Wang, Y.J. (2017) Discussion on Artificial Intelligence and Future Business Model. China Journal of Commerce, 17, 132-133. (In Chinese)

[2] Xu, Z.J. (2017) 15 Ministries and Commissions Work Together to Build a New Generation of Innovative Open Platform for Artificial Intelligence in China. Science \& Technology Industry of China, 12, 80-81. (In Chinese)

[3] Zhang, M. (2016) Will Accountants and Tax Agents Be Replaced by Robots After Deloitte Introduces Artificial Intelligence? Wallstreetcn. https://wallstreetcn.com/articles/231439

[4] State Council (2017) Notice of the State Council on Printing a New Generation of Artificial Intelligence Development Plan. Central People's Government of the People's Republic of China. http://www.gov.cn/zhengce/content/2017-07/20/content_5211996.htm

[5] Chen, X.Z. (2017) "Artificial Intelligence" Storm in the Financial Field. Corporate Finance, 10, 88-89. (In Chinese) 
[6] Zhu, Y.Y. and Zhang, J.S. (2018) Application and Development of AI in Accounting Industry. China Township Enterprises Accounting, 6, 264-265. (In Chinese)

[7] Chen, K. (2017) Research on the Application of Intelligent Accounting Information System in G Tobacco Business Enterprises. Xi'an University of Post and Telecommunications. (In Chinese)

[8] Ministry of Finance of the People's Republic of China (2016) Research Report on the Supply and Demand of Accounting Talents in China. Central People's Government of the People's Republic of China.

http://kuaiji.firstacc.cn/a/20161022/5196.html

[9] Hu, L.R. (2016) Analysis of Computerized Accounting Teaching Mode in Colleges and Universities in the Internet+ Times. Modern Economic Information, 17, 271. (In Chinese)

[10] Lian, X.L. (2006) Discussion on the Current Structural Contradiction of Accounting Talents in China and Its Countermeasures. Contemporary Manager, 21, 942-943. (In Chinese)

[11] Ministry of Finance of the People's Republic of China (2016) Notice on Printing and Distributing the Outline of the 13th Five-Year Plan for Accounting Reform and Development. Central People's Government of the People's Republic of China. http://kjs.mof.gov.cn/zhengwuxinxi/zhengcefabu/201610/t20161018_2437976.html 